2018

\title{
Professional Behaviors and Fieldwork: A Curriculum Based Model in Occupational Therapy
}

Gabrielle R. Hackenberg

Thomas Jefferson University

Susan Toth-Cohen

Thomas Jefferson University

Follow this and additional works at: https://encompass.eku.edu/jote

Part of the Occupational Therapy Commons

\section{Recommended Citation}

Hackenberg, G. R., \& Toth-Cohen, S. (2018). Professional Behaviors and Fieldwork: A Curriculum Based Model in Occupational Therapy. Journal of Occupational Therapy Education, 2 (2). https://doi.org/10.26681/jote.2018.020203

This Original Research is brought to you for free and open access by Encompass. It has been accepted for inclusion in Journal of Occupational Therapy Education by an authorized editor of Encompass. For more information, please contact Linda.Sizemore@eku.edu. 


\title{
Professional Behaviors and Fieldwork: A Curriculum Based Model in Occupational Therapy
}

\begin{abstract}
Professional behaviors have been identified as imperative for fieldwork success in occupational therapy, and are held to high expectations by fieldwork educators. This study consisted of three phases. Phase one was a retrospective analysis of past Fieldwork Performance Evaluations (FWPE; $n=319$ ). Phase two consisted of the development of a curricular model and Level I Fieldwork Seminar with a focus on low-scoring professional behaviors on the FWPEs, which included verbal/ non-verbal communication, written communication, professional responsibility, work behaviors, and time management. Finally, phase three was a review of the course by the Philadelphia Region Fieldwork Consortium and edits to the seminar based on their feedback. Two theories, situated cognition and self-directed learning, were used to guide the curriculum development.
\end{abstract}

\section{Keywords}

Fieldwork, professional behaviors, occupational therapy education

\section{Creative Commons License}

\section{(c) 1 (i)}

This work is licensed under a Creative Commons Attribution-Noncommercial-No Derivative Works 4.0 License. 


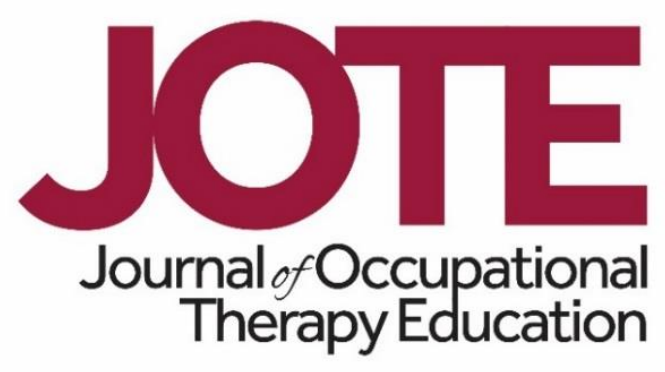

Volume 2, Issue 2

\title{
Professional Behaviors and Fieldwork: A Curriculum Based Model in Occupational Therapy
}

Gabrielle Hackenberg, OTD, MS, OTR/L ${ }^{1}$ and Susan Toth-Cohen, $\mathrm{PhD}$, OTR/L ${ }^{2}$

University of the Sciences ${ }^{1}$ and Thomas Jefferson University ${ }^{2}$

United States

\begin{abstract}
Professional behaviors have been identified as imperative for fieldwork success in occupational therapy, and are held to high expectations by fieldwork educators. This study consisted of three phases. Phase one was a retrospective analysis of past Fieldwork Performance Evaluations (FWPE; $n=319$ ). Phase two consisted of the development of a curricular model and Level I Fieldwork Seminar with a focus on lowscoring professional behaviors on the FWPEs, which included verbal/ non-verbal communication, written communication, professional responsibility, work behaviors, and time management. Finally, phase three was a review of the course by the Philadelphia Region Fieldwork Consortium and edits to the seminar based on their feedback. Two theories, situated cognition and self-directed learning, were used to guide the curriculum development.
\end{abstract}

\section{INTRODUCTION}

Professional behaviors have been identified as imperative for fieldwork success and held to high expectations by fieldwork educators (Campbell \& Corpus, 2015; Koenig, Johnson, Morano, \& Ducette, 2003; Robinson, Tanchuk, \& Sullivan, 2012). Professional behaviors include communication skills, initiative, clinical reasoning, common sense, ability to handle stress, interpersonal skills, and interest in learning (Campbell \& Corpus, 2015; Gutman, McCreedy \& Heisler, 1998; James \& Musselman, 2006; Kasar \& Muscari, 2000; Koenig et al., 2003; Scheerer, 2003). Moreover, studies such as that completed by James and Musselman (2006) have found that the most common characteristics of students who have failed fieldwork are poor professional behaviors. However, few studies exist that offer ways in which professional behaviors necessary for successful performance in fieldwork can be addressed during a student's academic preparation. Additionally, it is unclear how these poor professional behaviors can be 
identified and addressed in academic courses. In academic settings, these characteristics present as unprofessional attitudes and behaviors, not poor academic performance, and may be sporadically and inconsistently addressed by faculty throughout academic coursework (Gutman et al., 1998). Brehm et al. (2006) identified that a more structured approach in teaching professional behaviors can "enhance students' abilities to identify and assimilate the values and behaviors associated with professionalism" (p.1).

Professional behaviors is a topic that must be openly taught and evaluated on three levels: the individual, inter-personal, and societal/institutional (Mason, Vitkovitch, Lambert, \& Jepson, 2014). However, professional behaviors is a challenging topic to teach, difficult to observe, and difficult to assess. It is challenging because most of what is considered professional behaviors may be viewed as abstract and learning involves "long-term experience and reflection" on the environments in which attitudes and behaviors are demonstrated, something which may be difficult to achieve in the length of time required to complete an academic program (Mason et al., 2014, p. 97).

\section{LITERATURE REVIEW}

Few studies have been conducted to date that look at the commonalities among unsuccessful Level II fieldwork experiences and professional behaviors. James and Musselman (2006), in a study of 11 fieldwork educators, identified "poor behaviors" as the most common characteristic of students who failed Level II fieldwork experiences. The fieldwork educators ranked student behaviors from most frequent to least. The behaviors included: poor problem solving skills, poor clinical reasoning skills, difficulty responding to constructive criticism, lacking initiative and carryover, difficulty getting the "big picture," and poor organizational skills. In evaluating the students according to the American Occupational Therapy Association (AOTA) Fieldwork Performance Evaluation for the Occupational Therapy Student (FWPE), judgment was identified as the most problematic area. From this study, it was suggested that academic programs take on a more problem-based learning (PBL) approach to classroom education in order to develop clinical reasoning skills and independent thinking. Another suggestion was to ensure a good communication system between the academic program and the fieldwork site (James \& Musselman, 2006).

Campbell and Corpus (2015) examined the perspectives of fieldwork educators on the professional behaviors of Level II fieldwork students. They asked 296 fieldwork educators to complete two surveys, revealing that the professional behaviors that correlated to specific sections in the FWPE as being strongly influential on the successful completion of Level II fieldwork were: responsibility, constructive feedback, time management, and interpersonal skills. Gutman et al. (1998) and Scheerer (2003) noted the following characteristics as interfering with successful performance in fieldwork: rigidity of thinking, lack of insight, externalization of responsibility, discomfort in the ambiguity that accompanies clinical reasoning, difficulty interpreting feedback and learning from mistakes, and dependence on external measures for self-esteem. 
In assessing the best practices for the education of professional behaviors, teaching positive professional behaviors was found to lead to success in fieldwork (Scheerer, 2003). It is recommended that material is presented throughout the curriculum in a structured approach, learning professional behaviors should be considered a process rather than a fixed construct, and it must be taught and assessed in multiple ways (Brehm et al., 2006; Mason et al., 2014). Teaching methods include role modeling, practice/experience opportunities, small group discussion, reading assignments, formal advisor meetings/mentoring, and lectures (Cruess \& Cruess, 2006; Davis, 2009; Finn, Garner, \& Sawdon, 2010; Mason et al., 2014). Students should also be educated on emotional intelligence, as understanding emotions and emotional self-management techniques was found to be linked to skills in communication, increased client centeredness, and increased intervention skills (Andonian, 2013; Brown, Williams, \& Etherington, 2016).

Evaluation of professional behaviors is known to be critical to the successful implementation and the achievement of individual goals (Hodges et al., 2011; Koenig et al., 2003). These evaluations should be formative, frequent, rigorous, and followed by one or more methods of remediation. Assessment can include one or more of the following options: student survey/self-assessment, faculty feedback, and statistical analysis of professionalism profiles (Hodges et al., 2011; Mason et al., 2014). Student self-assessment should be self-directed and supports the development of cognition, affect, and performance (Ledet et al., 2005). Self-assessment and reflection is seen as imperative to the integration of educational content and life experiences, increases communication skills, and is best achieved through the use of journals, feedback, and peer group discussion (Zimmerman et al., 2007). Remedial instruction in the academic setting for poor professional behaviors, utilizing methods such as seminars, faculty feedback, counseling, community volunteer work, and student learning contracts have all been observed to be successful ways to address poor professional behaviors in academic preparation (Cruess \& Cruess, 2006; Gutman et al., 1998; Ledet et al., 2005; Mason et al., 2014; Randolph, 2003; Scheerer, 2003).

Thus, professional behaviors are seen as crucial to success in fieldwork education and studies have noted that the most common characteristics of students who have failed fieldwork are poor professional behaviors, yet little research exists to identify how these behaviors are observed and addressed in academic settings. Through the use of both the theory of situated cognition and self-directed learning (SDL) theory, this study examined the scores that students from one university scored on questions related to professional behaviors. This information was then used to revise the occupational therapy curriculum at a university in the northeastern United States and to create a Level I fieldwork seminar that focuses on educating students on professional behaviors and preparing them for successful performance in these areas during fieldwork experiences. 


\section{Theoretical Frameworks}

Two theories were used to understand the students' learning process and to guide curricular development: situated cognition and SDL. Together, these two theories allowed for the appreciation that occupational therapy education and practice occurs outside the classroom and within "authentic activity" (American Institutes for Research, 2011; Schell \& Schell, 2008, p. 337). Both theories are based on the idea that learning is integrated into daily routines and activities and it is a function of living. They both also posit that particular life experiences, both negative and positive, could act as a barrier to education (American Institutes for Research, 2011; Merriam, 2001; Schell \& Schell, 2008).

Fieldwork allows students to apply didactic learning, including theoretical and scientific principles, into real world situations in a variety of settings. It is during these fieldwork experiences that students develop competence in "applying the occupational therapy process" and incorporating evidence-based interventions to meet the needs of their clients through supervisor-led and self-directed learning methods (Costa, 2015, p. 3). These two theories link directly to fieldwork in their focus on context specific learning and experience based education.

Theory of situated cognition. The theory of situated cognition poses that learning cannot be separated from the situation in which that learning takes place, and that learning occurs only when people interact with the community, the tools available to them, and the activity presented to them (Merriam, Caffarella, \& Baumgartner, 2007). In a community role, "individuals must make a legitimate contribution to a situation that they value and consider 'authentic"' (Schell \& Schell, 2008, p. 272). Initially this involvement is likely to be on the "edges" of the social community, but as time passes and experiences increase, participation and complexity increase. Through this participation, individuals begin to construct their identity within the community, eventually leading to a mental "meaningfulness" (Schell \& Schell, 2008).

Within the theory of situated cognition, experiences are utilized to create an emphasis on authentic encounters in actual versus decontextualized contexts (Merriam et al., 2007). In order to create these experiences, the importance of cognitive apprenticeships is stressed, particularly for those being educated in an area of the health professions such as occupational therapy. These apprenticeships place an importance on teaching the learner various ways of thinking and the skills associated with the activities involved, and through discussion and collaboration with their supervisor students' "situated understanding" can be generalized and conceptual knowledge solidified (Schell \& Schell, 2008; Merriam et al., 2007). In addition to situated cognition, the theory of SDL allows for a student to accept ownership of their learning and that the learning that takes place is context specific.

Theory of self-directed learning. The theory of SDL, which is a sub-theory within adult learning theory, posits that the learner is characterized by an emphasis on individualism and egalitarianism, and that the learner becomes more self-directed and shows an increase in taking the initiative in their learning as they mature (American Institute for 
Research, 2011; Manning, 2007; Merriam, 2001). The learner takes initiative in their learning by determining their needs, creating goals, identifying resources, executing a plan to meet those goals, and evaluating the outcomes. A benefit of SDL is that learning occurs in everyday routines at the learner's convenience and according to their preferences (American Institute for Research, 2011).

Together, situated cognition and SDL theory inform the current study by promoting an understanding of how to best educate adult learners and how learning is best experienced in a health professional field. These theories provided a framework that enabled the first author to utilize best practice methods in teaching/demonstrating professional behaviors to occupational therapy students while recognizing the challenges that these students might face. In addition, they informed the author on the most successful way in which to impart an understanding of how important this information is to a student's future as a practicing clinician.

\section{METHODS}

\section{Design}

This research study was approved by the Thomas Jefferson University Institutional Review Board as an exempt study. The study consisted of three phases. Phase one was a retrospective review of past FWPEs (AOTA, 2002) of students in both of the two entry-level program tracks: masters (MOT) and doctoral (DrOT). Phase two consisted of the development of a curricular model with a focus on teaching and addressing professional behaviors. Finally, phase three was a review of the course by the Philadelphia Region Fieldwork Consortium (PRFWC) and edits to the course based on their feedback (see Figure 1 for an overview of the phases). There were two research questions that guided this study: 1) What percentage of students scored poorly on professional behaviors during Level II fieldwork, as measured by the FWPE? and 2) What can be added to the academic program to improve student performance of professional behaviors?

\section{Instrument}

The FWPE is designed to "measure the performance of the occupational therapy process... (and) to measure entry-level competence" (AOTA, 2002). This evaluation is used to score students on their performance throughout their two Level II fieldwork experiences. The student's performance is rated on a total of 42 items from fundamentals of practice to professional behaviors. Each item is given a score on a 1-4 scale which designates a particular level: the score of one equates to unsatisfactory, two is needs improvement, three is meets standards, and four is exceeds standards. To score at the level of "satisfactory performance" at midterm, a student must receive a score of 90 or above. To pass at the final a student must receive a score of 122 and above. 


\title{
Study Phases
}
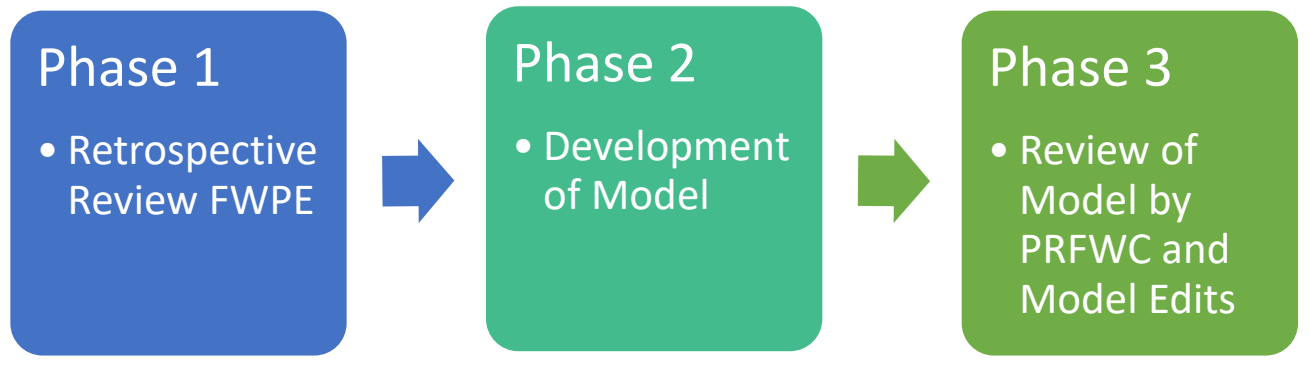

Figure 1. Study phases.

\begin{abstract}
Phase One
Completed FWPEs are kept on record at the University and available to the academic fieldwork coordinators for review as needed. A random selection of FWPEs from 20122016 of students in both the master's and doctoral tracks at the first author's university ( $n=319 ; 64 \%$ of those available) were reviewed, focusing on eleven specific questions and their scores. This particular number of evaluations was chosen based on those evaluations that were legible and were fully completed. These questions are found in Section VI (Communication) and VII (Professional Behaviors) of the FWPE and include: verbal and nonverbal communication, documentation, written communication, appropriate language, collaboration, professional responsibility, response to feedback, work behaviors, time management, interpersonal skills, and respect for diversity.
\end{abstract}

Descriptive statistics were used to analyze the FWPE scores. Since no students scored a 1 (unsatisfactory) in any category, only scores of 2 (needs improvement), 3 (meets standards), and 4 (exceeds standards) were included. The mean score for each of the eleven questions was calculated ( $n=319$; see Table 1).

Table 1

Scores from Sections VI and VII of the FWPE

\begin{tabular}{|l|c|c|c|c|}
\hline & $\begin{array}{c}\text { Mean Score } \\
(\mathrm{n}=319)\end{array}$ & $\begin{array}{c}\text { Needs } \\
\text { Improvement }\end{array}$ & $\begin{array}{c}\text { Meets } \\
\text { Standards }\end{array}$ & $\begin{array}{c}\text { Exceeds } \\
\text { Standards }\end{array}$ \\
\hline $\begin{array}{l}\text { Verbal/Nonverbal } \\
\text { Communication }\end{array}$ & 3.26 & $3.13 \%(10)$ & $67.17 \%(216)$ & $29.15 \%(93)$ \\
\hline $\begin{array}{l}\text { Documentation } \\
\text { Written }\end{array}$ & 3.31 & $1.88 \%(6)$ & $65.52 \%(209)$ & $32.60 \%(104)$ \\
\hline $\begin{array}{l}\text { Appropriate } \\
\text { Language }\end{array}$ & 3.34 & $3.45 \%(11)$ & $59.25 \%(189)$ & $37.30 \%(119)$ \\
\hline Collaboration & 3.20 & $0.94 \%(3)$ & $78.37 \%(250)$ & $20.69 \%(66)$ \\
\hline
\end{tabular}




\begin{tabular}{|l|c|c|c|c|}
\hline \multicolumn{1}{|c|}{$\begin{array}{c}\text { Table 1 } \\
\text { Continued }\end{array}$} & $\begin{array}{c}\text { Mean Score } \\
(\mathrm{n}=319)\end{array}$ & $\begin{array}{c}\text { Needs } \\
\text { Improvement }\end{array}$ & $\begin{array}{c}\text { Meets } \\
\text { Standards }\end{array}$ & $\begin{array}{c}\text { Exceeds } \\
\text { Standards }\end{array}$ \\
\hline $\begin{array}{l}\text { Response to } \\
\text { Feedback }\end{array}$ & 3.53 & $0.31 \%(1)$ & $46.71 \%(149)$ & $52.98 \%(169)$ \\
\hline $\begin{array}{l}\text { Work } \\
\text { Behaviors }\end{array}$ & 3.49 & $2.19 \%(7)$ & $46.71 \%(149)$ & $51.10 \%(163)$ \\
\hline $\begin{array}{l}\text { Time } \\
\text { Management }\end{array}$ & 3.34 & $4.08 \%(13)$ & $58.31 \%(186)$ & $37.62 \%(120)$ \\
\hline $\begin{array}{l}\text { Interpersonal } \\
\text { Skills }\end{array}$ & 3.59 & $0.00 \%(0)$ & $41.38 \%(132)$ & $58.62 \%(187)$ \\
\hline $\begin{array}{l}\text { Respect for } \\
\text { Diversity }\end{array}$ & 3.46 & $0.00 \%(0)$ & $53.92 \%(147)$ & $46.08 \%(172)$ \\
\hline
\end{tabular}

Red $=$ Percentage of 2 or more

\section{Phase Two}

The faculty of the occupational therapy program revised the entire curriculum for a more cohesive flow for students, based in part on this professional behavior research. The curricular change will be implemented within both the MOT and DrOT tracks. All courses within the didactic portion of both programs are taught on campus. Following the end of the second year the MOT students complete their Level II fieldwork consecutively and then graduate from the program. The DrOT students have an additional semester on campus before completing both Level II fieldworks during the third year, and then return to campus for the remainder of the doctoral components of the program.

The curriculum was developed with a focus on the poorest scoring professional behaviors identified during Phase 1. The researchers used scores of needs improvement with a percentage of 2 or higher as the cut off for determining which behaviors to focus on, because five out of the ten categories had scores of two percent or higher, with a range of $0.00 \%-4.08 \%$ (see Table 1 ). Therefore, the curriculum focused on the professional behaviors of verbal/ non-verbal communication, written communication, professional responsibility, work behaviors, and time management.

A Level I fieldwork seminar, taken during the students' first fall semester, was developed to address the identified professional behaviors. Modules defining Level I and Level II fieldwork and professional behaviors were included in the seminar, as well as two self-assessments and one faculty assessment to guide the students' understanding of their own professional behaviors (Self-Assessment of Professional Behaviors; University of the Sciences, adapted from the Philadelphia Region Fieldwork Consortium Level I Fieldwork Evaluation; Colorado State University Professional Behavior Assessment; Colorado State University) and time management skills (Time Structure Questionnaire; Brandeis University).

The creation of the seminar utilized the two theories, situated cognition and SDL, to choose activities that were appropriate for adult learners and matched closely with the tenets of fieldwork education. Examples of this include an assignment in which the 
students' record themselves completing an interview and later review the recording to comment on their professional behaviors throughout (active learning and self-initiated learning). An additional assignment that focused on learning in everyday routines includes time-management routines in which students analyze their routines to work on their time-management skills.

In the subsequent semesters following the seminar course, each student will complete the Self-Assessment of Professional Behaviors (University of the Sciences, adapted from the Philadelphia Region Fieldwork Consortium Level I Fieldwork Evaluation), advisors will complete the Colorado State University Professional Behavior Assessment (Colorado State University), and together will review both as well as the student's Professional Development Plan and revise as necessary. Remediation plans will be created for students who are identified as having concerns in professional behaviors. These plans are tailored towards each individual student but could include: faculty feedback, student self-reflection through journals, action plans or learning contracts, and additional assignments (Ledet et al., 2005; Scheerer, 2003; Zimmerman et al., 2007). Remediation plans may occur at any time throughout the curriculum and must be successfully completed prior to the start of Level II fieldwork placements.

\section{Phase Three}

An email was distributed to the twelve members of the PRFWC soliciting feedback on the seminar course along with a copy of an outline of the course that included course topics and activities. The PRFWC consists of academic professionals who represent occupational therapy fieldwork programs at colleges and universities in the Philadelphia area. The vision of this group states, "educational resource for fieldwork education at local, state and national levels" with a mission to "enhance the quality of occupational therapy education by facilitating collaboration and communication among our occupational therapy academic programs, fieldwork educators and our community" (Philadelphia Region Occupational Therapy Fieldwork Consortium, n.d.). Feedback was requested from this group in order to strengthen the modules for the Level I seminar as each member also spends time working with students on professional behaviors throughout their programs. Once feedback was received, edits to the course were completed and the course was finalized.

Responses were received from four members (33\%), of whom three (75\%) provided feedback. The feedback that was given was positive and included only a few minor suggestions/additions. Two members suggested moving the education on becoming a fieldwork educator to the end of the course; two members recommended allowing for various levels of education on use of time management tools to allow for variations in students' current level of understanding; for written communication, feedback was given on adding practical aspects of written communication such as APA use, appropriate response time for emails, among other factors. Finally, a suggestion was made to add self-advocacy to verbal communication skills. A full outline of the course can be found in Appendix A, including changes made based on PRFWC feedback. 


\section{DISCUSSION}

Mason et al. (2014) advised that professional behaviors must be openly taught and evaluated on a multitude of levels, but that this is a challenging area to teach, observe, and assess. A previous study by Gutman et al. (1998) indicated it is unclear how poor professional behaviors can be identified and addressed in academic courses. Brehm et al. (2006) identified that a more structured approach in teaching professional behaviors will enhance the ability of students to integrate the values and beliefs associated with professionalism. Overall, it was determined that occupational therapy students would benefit from an explicit education on professional behaviors throughout the didactic portion of their program. Through this study, specific areas of professional behaviors were identified to be addressed, including: verbal/nonverbal communication, written communication, professional responsibility, work behaviors, and time management. Curricular changes can be made to address these areas through the creation of fieldwork seminars and continual review of each student's professional behaviors via both faculty and self-assessments along with the creation of professional development plans.

Limitations of this study include a relatively small sample size (only one university), as well as a selection of students only in the northeastern region of the United States. An additional limitation is the subjective nature of the rating scale for the FWPE. No two educators scored the same way, leaving a large variability in scores that students received, even among the same students' two Level II fieldworks. Implications from this study for other academic fieldwork coordinators or occupational therapy programs include: understanding the effects that professional behaviors have on a students' Level II fieldwork performance/success in addition to ways in which to address the education and remediation of professional behaviors in the academic setting. Further studies could look at the success of this curricular model as well as student scores on the FWPE at other universities. It is recommended that a follow-up study compare FWPE scores pre and post addition of this curricular model.

\section{CONCLUSION}

Professional behaviors are essential to occupational therapy students' success in academics and fieldwork and must be taught throughout their time in a graduate program in order for them to be well-rounded entry-level practitioners at the completion of their studies. To achieve this, a curricular model addressing professional behaviors from the start of the program may be beneficial, and includes a fieldwork seminar, remediation plans, as well as both faculty and self-assessments.

\section{References}

American Institutes for Research. (2011). TEAL Center fact sheet No. 11: Adult learning theories. Teaching Excellence in Adult Literacy. Retrieved from https://lincs.ed.gov/sites/default/files/11 \%20TEAL Adult Learning Theory.pdf

American Occupational Therapy Association. (2002). Fieldwork Performance Evaluation for Occupational Therapy Student [Evaluation form]. American Occupational Therapy Association Press. 
Andonian, L. (2013). Emotional intelligence, self-efficacy, and occupational therapy students' fieldwork performance. Occupational Therapy in Health Care, Early Online, 1-15. https://doi.org/10.3109/07380577.2012.763199

Brehm, B., Breen, P., Brown, B., Long, L., Smith, R., Wall, A., \& Warren, N.S. (2006). An interdisciplinary approach to introducing professionalism. American Journal of Pharmaceutical Education, 70(4), 1-5. https://doi.org/10.5688/aj700481

Brown, T., Williams, B., \& Etherington, J. (2016). Emotional intelligence and personality traits as predictors of occupational therapy students' practice education performance: A cross-sectional study. Occupational Therapy International, 23, 412-424. https://doi.org/10.1002/oti.1443

Campbell, M.K. \& Corpus, K. (2015). Fieldwork educators' perspectives: Professional behavior attributes of Level II fieldwork students. Open Journal of Occupational Therapy, 3(4), 1-13. https://doi.org/10.15453/2168-6408.1146

Colorado State University (n.d.). Colorado State University Professional Behavior Assessment [Assessment form].Retrieved from www.ot.chhs.colostate.edu/students/files/Student\%20Handbook\%202013-14.pdf

Costa, D.M. (ed). (2015). The essential guide to occupational therapy fieldwork education: Resources for educators and practitioners ( $2^{\text {nd }}$ ed). Bethesda, MD: AOTA Press.

Cruess, R.L., \& Cruess, S.R. (2006). Teaching professionalism: General principles. Medical Teacher, 28(3), 205-208. https://doi-org.db.usciences.edu/10.1080/01421590600643653

Davis, D.S. (2009). Teaching professionalism: A survey of physical therapy educators. Journal of Allied Health, 38(2), 74-80.

Finn, G., Garner, J., \& Sawdon, M. (2010). 'You're judged all the time!' Students' views on professionalism: A multicentre study. Medical Education, 44, 814-825. https://doi-org.db.usciences.edu/10.1111/j.1365-2923.2010.03743.x

Gutman, S.A., McCreedy, P., \& Heisler, P. (1998). Student Level II fieldwork failure: Strategies for intervention. American Journal of Occupational Therapy, 52(2), 143-149. https://doi.org/10.5014/ajot.52.2.143

Hodges, B. D., Ginsburg, S., Cruess, R., Cruess, S., Delport, R., Hafferty, F., ... \& Rees, C. (2011). Assessment of professionalism: Recommendations from the Ottawa 2010 conference. Medical Teacher, 33, 354-363. https://doi.org/10.3109/0142159X.2011.577300

James, K.L., \& Musselman, L. (2006). Commonalities in Level II fieldwork failure. Occupational Therapy in Health Care, 19(4), 67-81. https://doi-org.db.usciences.edu/10.1080/J003v19n04 05

Kasar, J. \& Muscari, M.E. (2000). A conceptual model for the development of professional behaviours in occupational therapists. Canadian Journal of Occupational Therapy, 67(1), 42-50. https://doi.org/10.1177/000841740006700107

Koenig, K., Johnson, C., Morano, C.K., \& Ducette, J.P. (2003). Development and validation of a professional behavior assessment. Journal of Allied Health, 32(2), 86-91. 
Ledet, L., Esparza, C.K., \& Peloquin, S.M. (2005). The conceptualization, formative evaluation, and design of a process for student professional development. American Journal for Occupational Therapy, 59, 457-466. https://doi.org/10.5014/ajot.59.4.457

Manning, G. (2007). Self-directed learning: A key component of adult learning theory. Journal of the Washington Institute of China Studies, 2(2), 1-6.

Mason, R., Vitkovitch, J., Lambert, R., \& Jepson, J. (2014). Knowing about and performing professionalism: Developing professionalism in interprofessional healthcare education. PBLH, 2(1), 96-107. https://doi.org/10.11120/pblh.2013.00027

Merriam, S.B. (2001). Andragogy and self-directed learning: Pillars of adult learning theory. New Directions for Adult and Continuing Education, 89, 3-13. https://doi.org/10.5014/ajot.59.4.457

Merriam, S.B., Caffarella, R.S., \& Baumgartner, L.M. (2007). Learning in adulthood: A comprehensive guide ( $3^{\text {rd }}$ ed). San Francisco, CA: Jossey-Bass.

Philadelphia Region Occupational Therapy Fieldwork Consortium. (n.d.). Retrieved from http://www.philaotfwconsortium.org/

Randolph, D.S. (2003). Evaluating the professional behaviors of entry-level occupational therapy students. Journal of Allied Health, 32(2) 116-121.

Robinson, A.J., Tanchuk, C.J., \& Sullivan, T.M. (2012). Professionalism and occupational therapy: An exploration of faculty and students' perspectives. Canadian Journal of Occupational Therapy, 79(5), 275-284. https://doi.org/10.2182/cjot.2012.79.5.3

Scheerer, C.R. (2003). Perceptions of effective professional behavior feedback: Occupational therapy student voices. American Journal of Occupational Therapy, 57, 205-217. https://doi.org/10.5014/ajot.57.2.205

Schell, B.A.B. \& Schell, J.W. (2008). Clinical and professional reasoning in occupational therapy. Baltimore, MD: Lippincott Williams \& Wilkins.

University of the Sciences. (2016). Self-assessment of professional behaviors [Assessment form].

Zimmerman, S.S., Hanson, D.J.B., Stube, J.E., Jedlicka, J.S., \& Fox, L. (2007). Using the power of student reflection to enhance professional development. Internet Journal of Allied Health Sciences and Practice, 5(2), 1-7. 


\section{Appendix A}

\section{Course Outline}

\section{Module 1: Fieldwork}

- Lecture

- What professional responsibility is

- Level I and Level II FW

\section{Module 2: Professional Behaviors}

- Lecture

- Student Self-assessment (University of the Sciences) Completed 3x in seminar then each subsequent semester

- Colorado State University Professional Behavior Assessment (completed by course instructor, then advisors) $1 \mathrm{x} /$ semester

- Professional Development Plans - developed from two assessments and revised each semester with advisor

\section{Module 3: Time Management}

- Lecture

- "Time Structure Questionnaire" (Brandeis University) - 26 item self-assessment, reliable and valid, higher scores mean student has more time structure

- Activities

- Goal Setting

- Worksheet

- 3 goals: 1) school, 2) extracurricular, 3) friends/family

- Each goal then has three things needed to achieve these goals, followed by 3 things that are necessary to complete those previous 3 things (aka 3 goals with 9 steps)

- Exercise

- 3 reasons for each of those 3 goals explaining why the students want to meet those goals (additional questions)

- Scheduling \& Self-Monitoring

- Day Reconstruction Exercise

- Training in how to properly use a planner

\section{Module 4: Written Communication}

- Deliberate Practice

- APA review

- Strategies and Activities

$\circ$ Outlining/Planning

○ Drafting

○ Free Writing 
- Familiarize students with samples from desired genre

- Clearly Defined Writing Tasks

- How to respond:

- Response time

- Email length

- Activities

- Peer Review of assignments prior to submission

- Writing Groups/Workshops

- Daily writing assignments

- Read writing aloud

Module 5: Verbal and Nonverbal Communication

- Activities

- Class discussion

- Mandatory participation

- Preparation for discussion

- Interview assignment

- Observations in the community

- Communication Strategies used during OT interventions

- Self-Advocacy

- Nonverbal Communication

Module 6: Professional Responsibility and Work Behaviors

- Lecture

- Self-Regulated Learning

- Becoming a Fieldwork Educator

** Words in red $=$ behaviors identified through FWPE review as increased percentage of scores of 2

\section{Readings included in corresponding modules:}

American Occupational Therapy Association. (2015). Answers to your fieldwork questions. In Costa, D.M. (Ed.). The essential guide to occupational therapy fieldwork education: Resources for educators and practitioners ( $2^{\text {nd }}$ edition). (pp. 295-297). Bethesda, MD: AOTA Press.

American Occupational Therapy Association. (2015). Occupational therapy fieldwork education: Value and purpose. In Costa, D.M. (Ed.). The essential guide to occupational therapy fieldwork education: Resources for educators and practitioners (2nd edition). (pp. 3-4). Bethesda, MD: AOTA Press.

Andrews, J. (2000). The value of reflective practice: A student case study. The British Journal of Occupational Therapy, 63(8), 196-198. https://doi.org/10.1177/030802260006300807 
Daly-Cano, M., Vaccaro, A., \& Newman, B. (2015). College student narratives about learning and using self-advocacy skills. Journal of Posetsecondary Education and Disability, 28(2), 213-227.

Delullis, E.D. (2013). Fieldwork issues: Answering questions about level I fieldwork. OT Practice, 18(12), 8-9.

Hanson, D. (2012). Fieldwork issues: Wanted: Hands-on learning opportunities during level I fieldwork. OT Practice, 17(12), 7-8.

Henry, A.D. \& Kramer, J.M. (2009). The interview process in occupational therapy. In Willard, H.S., Crepeau, E.B., Cohn, E.S., \& Boyt Schell, B.A. Willard \& Spackman's occupational therapy, 11 th edition (pp. 342-358). Philadelphia, PA: Wolters Kluwer Health/Lippincott Williams \& Wilkins.

Lowenstein, N. \& Duncombe, L. (2002). Professional behaviors. In Sladyk, K (Ed). The successful occupational therapy fieldwork student (pp. 23-32). Thorofare, NJ: Slack Incorporated.

Schreiner, M.B. (2007). Effective self-advocacy: What students and special educators need to know. Intervention in School and Clinic, 42(5), 300-304. https://doi.org/10.1177/10534512070420050701

Tipton, D.J. (2017). Personal and professional growth in healthcare. In Tipton, D.J. Personal and professional growth in healthcare (pp. 1-22). Burlington, MA: Jones \& Bartlett Learning, LLC. 